\title{
The impact of hospital settings on the mood status of family care givers
}

\author{
Syed Muhammad Mustahsan, Rehan Shamim, Mustafa Mushtaq, Khalil Farooque, Rabeeya \\ Razzaque, Syed Faizan Hasnain, Syeda Sara Fatima, Amber Batool
}

Dow University of Health Sciences, Sindh Medical College, Pakistan

Correspondence: Syed Muhammad Mustahsan. Address: House No: A-15, Sector 14/B, Shadman Town, North Nazimabad, Karachi, Pakistan. E-mail: mustu198@gmail.com

Received: January 31, 2014

Dol : $10.5430 /$ jha.v3n5p144
Accepted: March 27, 2014

URL: http://dx.doi.org/10.5430/jha.v3n5p144

\section{Abstract}

Objective: This study aimed to find out the existing differences in anxiety and depression among patient's family care providers in public and private health sectors of Karachi.

Background: For family care givers, care-giving is extremely rewarding it makes a bond between patient and a care-giver. It makes a union which is indispensable for patient welfare. The wellness of caregiver depends on patient's condition and level of satisfaction with the circumstances associated with care-giving, undeniably care-giving constitute myriad of stresses, like depression, anxiety, frustration which if not addressed can have serious impact on caregivers health and can even make them resentful of their role as well. The present study was conducted to investigate the major mood changes among patients' family care givers in public and private health sectors.

Method: A cross-sectional study was carried at Jinnah Postgraduate Medical Centre (Public Health Sector) and Liaquat National Hospital (Private Sector) from 1st March till 1st August, 2013. The study was conducted on the family care givers of the patients residing with them at the hospitals. Hospital Anxiety and Depression Scale (HADS) was completed by 288 participants out of 290 caregivers who enrolled in the study. The HADS was used to evaluate the factors and symptoms of mood disorder (anxiety and depression) in the caregivers of patients.

Results: Out of 288 participants who completed the HADS, 223 showed a high rate of psychological disturbed state which was more prevalent in the females (79.8\%) than males (75.1\%). The HADS was equally filled by the caregivers at public health sector $(n=145)$ and private health sector $(n=145)$. The total cases of mood disorder is relatively high in the caregiver population and most of the cases were found in public health sector $(n=134)$ as compared with private health sector $(\mathrm{n}=89)$.

Conclusion: Anxiety and depression among the patients family care providers was very appreciable especially in Public Health Sector as compared to Private Health Sector perhaps due to economic burden, doctor-family caregiver relationship and negligence of concerned authorities. We strongly suggest and request concerned authorities to reduce stress and enhance the quality of life of family care-provider.

\section{Key words}

Care givers, Stress, Anxiety, Depression 


\section{I ntroduction}

Over the past several decades, as medical science has achieved landmarks in almost every quarters but global burden of diseases yet paralleled. Depression is the fourth-leading cause of global disease burden and up to $20 \%$ of cases those attend primary health care suffer from often linked anxiety and depression in developing countries, but the symptoms of these conditions are not recognized ${ }^{[1]}$. Globally as of 2010 approximately 273 million (4.5\% of the population) had an anxiety disorder. It is more common in females (5.2\%) than males $(2.8 \%)^{[2]}$. Psychiatric morbidities are particularly problematic in developing countries as resources to measure its prevalence and solving the issue are seriously lacking as shown by Akhund, who reported a prevalence of $12 \%$ while MI et al. quoted a much higher figure of $38.4 \%$ both studies were conducted in Karachi, Pakistan but differed in their design based on Hospital Anxiety and Depression Scale ${ }^{[3]}$.

As the quality of patient care in most of third world countries like Pakistan is substantially low, patients and their attendants face uncleanliness within hospital premises especially in government setup, overcrowding, lack of bedding, shortage of medicines and lack of facilities are the most important factors responsible for dissatisfaction of patients and their relatives with medical care and result in mental stresses. Stress arises "when the demands imposed by a patient's condition collide with a caregiver's subjective ability to respond, or when these demands obstruct the pursuit of other objectives" ${ }^{[4]}$. Anxiety is a common psychological disorder experienced among family members of critically ill patients ${ }^{[5]}$. A study showed prevalence of anxiety in family caregivers of cancer patients was $38.1 \%$ and prevalence of depression was $82.2 \%$ in Korea ${ }^{[6]}$.

Mental stresses among family members of patients are often neglected which in turn leads to their decreased productivity and has other psychosocial implications. Purpose of this study was to find out existing psychiatric morbidity among patient attendants in two leading hospitals of Karachi.

\section{Method}

A cross-sectional study has been conducted from 1st March to 1st August, 2013 in tertiary care centers of Karachi. The data was collected from Jinnah Postgraduate Medical Centre (JPMC) and Liaquat National Hospital (LNH) from the family members of patients admitted with debilitating disorders at Surgical and Medicinal Departments in these tertiary care centers.

The participants were interviewed and investigated using the Hospital Anxiety and Depression Scale to allow evaluation of the prevalence and potential factors associated with symptoms of anxiety and depression ${ }^{[7]}$ during their stay with their patients at surgical, allied surgical, medicinal and allied medicinal wards of tertiary care centers.

The Hospital Anxiety and Depression Scale (HADS) is a 14-item self-report screening scale that was originally developed to indicate the possible presence of anxiety and depressive states. The HADS gives clinically meaningful results as a psychological screening tool, in clinical group comparisons and in co relational studies with several aspects of disease and quality of life ${ }^{[8]}$. HADS contains two parts: one for anxiety and one for depression each with a score range of 0-21 ${ }^{[9]}$. Each item had been answered by the patient on a four point (0-3) response category so the possible scores ranged from 0 to 21 for anxiety and 0 to 21 for depression. An analysis of scores on the two subscales of a further sample, in the same clinical setting, enabled provision of information that a score of 0 to 7 for either subscale could be regarded as being in the normal range, a score of 11 or higher indicating probable presence (casernes) of the mood disorder and a score of 8 to 10 being just suggestive of the presence of the respective state ${ }^{[10]}$.

Inclusion Criteria: The participants were acknowledged by patients as their relatives and most of the participants were residing at their homes. The subjects had no history of any chronic illnesses. 
Exclusion Criteria: The participants having any chronic illness were excluded from the study and those who were addictive were also excluded. Those relatives who were short visitors were also not considered.

Limitations: Although the researchers tried to conduct a detailed research but some limitations are always there. Indeed, due to short time course and shortage of funds we were unable to assess a large population and limited our study to only two tertiary centers. The subjects were evaluated only on the results of Hospital Anxiety and Depression Scale but were not clinically examined for the findings of anxiety and depression.

\section{Results}

A total of 290 caregivers were enrolled, of them 288 members completed the hospital anxiety and depression scale. $62.4 \%$ care-giver males and 37.6\% care-giver females participated in our study as shown in Table 1 . The scale was filled by the participants during their stay at tertiary care centers of Karachi, 145 from Jinnah Postgraduate Medical Centre (Public Hospital) and 145 from Liaquat National Hospital (Private Hospital). Rate of mood disorders were assessed in the care givers population. The total cases of mood disorder were 223 in a population of 288 showing a high rate of anxiety and depression in caregiver population. An extensive literature reports that mood disorders are more frequent in women compared with men ${ }^{[11]}$ as proved in our study that females (79.8\%) suffered more than males (75.1\%) shown in Table 2. Majority of these cases were under 40s; probably because people of this age prefer to stay at hospital with their patients and also because in our settings the participants were adults $(n=230)$ than elderly $(n=58)$.

Table 1. Percentage distribution of target population by gender

\begin{tabular}{llll}
\hline & Frequency & Percent & Valid Percent \\
\hline Male & 181 & 62.4 & 62.4 \\
Female & 109 & 37.6 & 37.6 \\
Total & 290 & 100.0 & 100.0 \\
\hline
\end{tabular}

Table 2. A cross tab between gender and mood disorder

\begin{tabular}{|c|c|c|c|c|c|}
\hline & & & \multicolumn{2}{|c|}{ Gender } & \multirow{2}{*}{ Total } \\
\hline & & & Male & Female & \\
\hline \multirow{6}{*}{$\begin{array}{l}\text { Mood } \\
\text { Disorders }\end{array}$} & \multirow{2}{*}{ Non-Case } & Count & 32 & 15 & 47 \\
\hline & & $\%$ within Gender & $17.7 \%$ & $13.8 \%$ & \\
\hline & \multirow{2}{*}{ Borderline Case } & Count & 12 & 7 & 19 \\
\hline & & $\%$ within Gender & $6.6 \%$ & $6.4 \%$ & \\
\hline & \multirow{2}{*}{ Case } & Count & 136 & 87 & 223 \\
\hline & & \% within Gender & $75.1 \%$ & $79.8 \%$ & \\
\hline Total & & Count & 181 & 109 & 290 \\
\hline
\end{tabular}

Note. Percentages and totals are based on respondents.

The cases of mood disorder were more prevalent in JPMC $(n=134)$ showing a high rate of affected caregiver population in Public Hospital whereas in LNH only $(\mathrm{n}=89)$ of caregivers showed cases of mood disorder as shown in the figure. We administered the scale at surgery $(n=60)$, medicine $(n=47)$, allied medicine $(n=127)$ and allied surgery $(n=54)$ wards but mood disorders were more prevalent in the caregivers of patients at surgery ward which may be due to the burden of surgical environment and complicated operative procedures done on their patients as shown through Table 3 . The average stay of the patients admitted with debilitating disorders was around two weeks depending on the health status of the patient.

The research protocol was approved by the ethical review board and an informed consent was taken from the enrolled participants without providing any financial incentives. 
Table 3. A cross tab between wards and mood disorder

\begin{tabular}{|c|c|c|c|c|c|c|c|}
\hline & & & \multicolumn{4}{|c|}{ Wards } & \multirow{2}{*}{ Tota } \\
\hline & & & Surgery & Allied Surgery & Allied Medicine & Medicine & \\
\hline \multirow{6}{*}{$\begin{array}{l}\text { Mood } \\
\text { Disorders }\end{array}$} & \multirow{2}{*}{ Non-Case } & Count & 3 & 12 & 7 & 25 & \multirow[t]{2}{*}{47} \\
\hline & & \% within wards & $5.0 \%$ & $22.2 \%$ & $14.9 \%$ & $19.7 \%$ & \\
\hline & \multirow{2}{*}{$\begin{array}{l}\text { Borderline } \\
\text { Case }\end{array}$} & Count & 2 & 5 & 0 & 11 & \multirow[t]{2}{*}{18} \\
\hline & & \% within wards & $3.3 \%$ & $9.3 \%$ & $0.0 \%$ & $8.7 \%$ & \\
\hline & \multirow{2}{*}{ Case } & Count & 55 & 37 & 40 & 90 & \multirow[t]{2}{*}{222} \\
\hline & & $\%$ within wards & $91.7 \%$ & $68.5 \%$ & $85.1 \%$ & $70.9 \%$ & \\
\hline Total & & Count & 60 & 54 & 47 & 127 & 288 \\
\hline
\end{tabular}

Note. Percentages and totals are based on respondents.

Figure. Graph on the prevalence of mood disorder at tertiary care hospitals

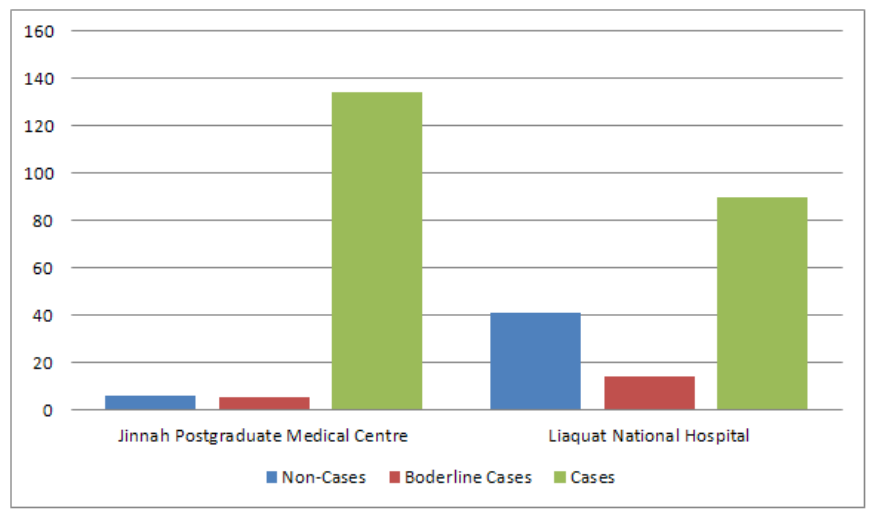

\section{Discussion}

Providing care at hospital is multidimensional, burdensome and trustworthy task which requires the utter co-ordination between professionals and family care providers. One should be mentally, socially and physically sound to bare such a huge responsibility. But unfortunately, in developing countries like Pakistan majority of the people are from low socioeconomic status, they are not familiar with ins and outs of providing accurate care, that's why they are more prone to mental illness ${ }^{[12]}$. It might be because of poverty and lack of jobs and many other factors which compel them in the house of anxiety and depression disorders which indeed impacts non-affirmatively on the life later on ${ }^{[13]}$.

A lot of work has been done on family care giving to determine whether it has declining or improving impact on health of caregivers and how it finds it gateway to the systemic manifestations among them ${ }^{[14,15]}$. Also, a past research showed that chronic stress in family caregivers has declined immunologic consequences ${ }^{[16]}$, which pushed our interest to study the frequency of suspected stress and anxiety disorders among family caregivers, the difference of their occurrences between private and public sector hospital setup.

In the setup of private and government hospitals the giant difference is reported in our study, mood disorders were more frequent in public sector hospital JPMC $(n=134)$ than private sector. LNH $(n=89)$ as shown in the figure, it was noticed that the proportion of non-cases were also high in private sector hospital which also represents their positive part. It was also found that the percentage of females prone to mood disorders is higher in comparison to males, i.e., females $=79.8 \%$ and males $=75.1 \%$.

Family care givers whose patients were admitted in major wards likely surgery wards and allied medicine wards $91 \%$ and $85 \%$, respectively, were found to be affected significantly. This difference can probably be due to difference in occupying capacities of these major wards and may be due to debilitating cases admitted in these wards. 
Studies show that social services support or interventions aimed at providing the emotional support to the caregivers have significant effect on reducing this burden ${ }^{[17]}$, proper counseling and hands on training of the caregivers can contribute to lower the stress and improve their quality of life ${ }^{[18]}$.

There were certain limitations to this study, including the cross-sectional design which does not possess any control group which limits the conclusions about directionality and we were also not funded and were short of time to extend our study to find out the factors responsible for such mood disturbances in the care givers, but we can see from previous studies, the factors which were generally responsible for causing mood disturbances among the family care givers can be: Patient related factors (presence of chronic illness, age of patient, severity of illness) ${ }^{[19]}$, Family related factors (stigma, cultural prohibition, spouse, one's health status, female gender ${ }^{[20]}$, desire of professional psychological help, help being received by GPs), Hospital related factors (absence of regular physicians, nurse meetings, absence or deficiency of beds, no waiting area, perceived contradictions in the information provided by faculty) ${ }^{[21]}$.

Endorsement of proactively aggressive care giving strategies moderates the relation between the caregiver mental health and potentially harmful care giving behavior ${ }^{[22]}$. In order to lower the global burden of mood disorder which came out to be $4.5 \%$ globally in $2010^{[2]}$, this is one of the step needed that we took by lending hands to the era of care giving.

Additionally, the look is required for the prevalence of mood disorders among the professional caregivers and its effects on the professional and family caregiver's interrelation ships which we limited to the family care givers in our study because of the lacking time and funds we required.

In this regard, the findings underscore the new experiments and researches and new and better policies should be implemented in order to provide justified care and services at both sectors of hospitals so that our hospital network will be flourished and become an exemplar of comfortable peaceful place for family caregivers too.

\section{Conclusion}

After the efforts made by researchers it is crystal clear that family care givers are exposed to instantaneous burden and strain, and the load of mood disturbances is a common feature among the family care givers at the Public sector hospitals. While managing the patients, physician should also keep their eye on care givers who are staying with their patients. Public sector hospitals are unsuccessful in the race of providing peace of mind and proper counseling to the family care givers. This drawback of Public sector hospital can become the reason for failing of the vision, i.e., health for everyone, that should be the motto of every health service provider and in future times it might lead to reluctant and hesitant attitude of people further restricting their access to the public hospitals. Therefore, it should shake the mind of the concerned health care authorities. Though the past researches have already picked out possible factors for such mood disturbances in family care givers and the whole community of researchers is contributing to the field, the problems is still in taking stand by the responsible people of health care sectors and play their part. Our study requests the stakeholders of concerned authorities to take strong measures on the Public Health Sectors and improve it for the betterment of their people.

\section{References}

[1] Worley, Heidi. Depression a leading contributor to global burden of disease. Washington: Population Reference Bureau. 2006.

[2] Vos, Theo, et al. Years lived with disability (YLDs) for 1160 squeal of 289 diseases and injuries 1990-2010: a systematic analysis for the Global Burden of Disease Study 2010. The Lancet. 2013; 2163-2196.

[3] Ali, Badar S., Imtiaz Jehan, Hashirn Reza. Development of an indigenous screening instrument in Pakistan: the Aga Khan University Anxiety and Depression Scale. Development. 1998.

[4] Raina, Parminder, et al. Care giving process and caregiver burden: conceptual models to guide research and practice. BMC pediatrics. 2004; 1. PMid: 14723791. http://dx.doi.org/10.1186/1471-2431-4-1 
[5] Siegel, M. D., Hayes, E., Vanderwerker, L. C., Loseth, D. B., Prigerson, H. G. Psychiatric illness in the next of kin of patients who die in the intensive care unit*. Critical care medicine. 2008; 36(6): 1722-1728. PMid: 18520637. http://dx.doi.org/10.1097/CCM.0b013e318174da72

[6] Park, Boyoung, et al. Prevalence and predictors of anxiety and depression among family caregivers of cancer patients: a nationwide survey of patient-family caregiver dyads in Korea. Supportive Care in Cancer. 2013; 1-9.

[7] Pochard, Frederic, et al. Symptoms of anxiety and depression in family members of intensive care unit patients: ethical hypothesis regarding decision-making capacity. Critical care medicine. 2001; 1893-1897. PMid: 11588447. http://dx.doi.org/10.1097/00003246-200110000-00007

[8] Herrmann, Christoph. International experiences with the Hospital Anxiety and Depression Scale-a review of validation data and clinical results. Journal of psychosomatic research. 1997; 17-41. http://dx.doi.org/10.1016/S0022-3999(96)00216-4

[9] Spinhoven, P. H., Ormel, J., Sloekers, P. P. A., Kempen, G. I. J. M., Speckens, A. E. M., Hemert, A. V. A validation study of the Hospital Anxiety and Depression Scale (HADS) in different groups of Dutch subjects. Psychological medicine. 1997; 27(2): 363-370. PMid: 9089829. http://dx.doi.org/10.1017/S0033291796004382

[10] Snaith, R. Philip. The hospital anxiety and depression scale. Health Qual Life Outcomes. 2003; 29. PMid: 12914662. http://dx.doi.org/10.1186/1477-7525-1-29

[11] Palanza, Paola. Animal models of anxiety and depression: how are females different? Neuroscience \&Bio behavioral Reviews. 2001; 219-233. http://dx.doi.org/10.1016/S0149-7634(01)00010-0

[12] Lorant, Vincent, et al. Socioeconomic inequalities in depression: a meta-analysis. American journal of epidemiology. 2003; 98-112. PMid: 12522017. http://dx.doi.org/10.1093/aje/kwf182

[13] Woodward, Lianne J., David M. Fergusson. Life course outcomes of young people with anxiety disorders in adolescence." Journal of the American Academy of Child \& Adolescent Psychiatry. 2001; 1086-1093. PMid: 11556633. http://dx.doi.org/10.1097/00004583-200109000-00018

[14] Lee, Sunmin, et al. Caregiving and risk of coronary heart disease in US women: a prospective study. American journal of preventive medicine. 2003; 113-119. http://dx.doi.org/10.1016/S0749-3797(02)00582-2

[15] Schulz, Richard, Scott R. Beach. Caregiving as a risk factor for mortality. JAMA: the journal of the American Medical Association. 1999; 2215-2219. PMid: 10605972. http://dx.doi.org/10.1001/jama.282.23.2215

[16] Kiecolt-Glaser, Janice K., et al. Chronic stress and immunity in family caregivers of Alzheimer's disease victims. Psychosomatic Medicine. 1987; 523-535. PMid: 3671639. http://dx.doi.org/10.1097/00006842-198709000-00008

[17] Lopez-Hartmann, Maja, et al. The effect of caregiver support interventions for informal caregivers of community-dwelling frail elderly: a systematic review. International journal of integrated care. 2012; 12.

[18] Kalra, Lalit, et al. Training carers of stroke patients: randomised controlled trial. Bmj. 2004; 1099. PMid: 15130977. http://dx.doi.org/10.1136/bmj.328.7448.1099

[19] Mc Cullagh, Emily, et al. Determinants of caregiving burden and quality of life in caregivers of stroke patients. Stroke. 2005; 2181-2186. PMid: 16151029. http://dx.doi.org/10.1161/01.STR.0000181755.23914.53

[20] Gallagher, Dolores, et al. Prevalence of depression in family caregivers. The gerontologist. 1989; 449-456. PMid: 2521102. http://dx.doi.org/10.1093/geront/29.4.449

[21] Biola, Holly, et al. Physician Communication with Family Caregivers of Long-Term Care Residents at the End of Life. Journal of the American Geriatrics Society. 2007; 846-856. PMid: 17537084. http://dx.doi.org/10.1111/j.1532-5415.2007.01179.x

[22] Shaffer, David R., W. Keith Dooley, Gail M. Williamson. Endorsement of proactively aggressive caregiving strategies moderates the relation between caregiver mental health and potentially harmful caregiving behavior. Psychology and Aging. $2007 ; 494$. PMid: 17874950. http://dx.doi.org/10.1037/0882-7974.22.3.494 